\title{
Mothers' behavioral models 6 years after the birth of a sole child by caesarean section
}

\author{
Olga Lubimova ${ }^{1, *}$, Elena Petukhova ${ }^{1}$, Galina Kravchenko ${ }^{1}$, and Nadezhda Kaigorodova ${ }^{1}$ \\ ${ }^{1}$ Altai State University, 656049, 61a Lenina ave., Barnaul, Russia.
}

\begin{abstract}
This article presents a comparison of the behavioral patterns of mothers for single children of 6-7 years of age who gave birth naturally, in emergency (a forced measure during the abnormal course of natural childbirth), or in a planned cesarean section.
\end{abstract}

\section{Introduction}

The proportion of babies born by cesarean section is becoming more important every year. Today, this is one of the most common operations, which is not only planned by doctors for medical reasons, but also is voluntarily elected by women. Practical experience of clinicians and child psychologists shows that children born through cesarean section are different from children born through natural birthmarks, primarily in terms of their physiological characteristics [1,2].

There are few reliable data on the psychological characteristics of such children, but they are partially contradictory. However, the range of factors that can influence neurophysiology and brain psychology is so wide that it is quite problematic to conduct an ideally planned empirical study. There are data $[3,4,5]$ that a child (up to 3 years old) born with the help of the abdominal delivery method (emergency and planned cesarean section) has a deficit development of attention, spatial thinking, passive and active vocabulary, arbitrariness in behavior management, as well as mood swings.

Meanwhile, a sufficient empirical base has been accumulated, evidencing the role of maternal behavior in the formation of the psychic and psychological properties of the personality, as well as psychological characteristics of the personality of a woman being prone to the elective caesarean section [6]. The immaturity of the parent relationship is distinguished among these features $[7,8]$.

There is a still discussion (for psychology and psychophysiology) question of what determines the personality characteristics of a child, the way of birth or postnatal influences provided by maternal behavior? To what extent do the personal characteristics of the mother contribute to the decision to have cesarean section? Studies on the predisposition and consequences of caesarean section are concentrated around the period of pregnancy and infancy. The purpose of our pilot study is a comparative analysis of the above models of maternal behavior that are separated from the moment of the birth of a single child 6-7 years.

* Corresponding author: lubimovaom@gmail.com 


\section{Materials and methods}

1. The questionnaire of satisfaction with marriage by V. V. Stolina, T. A. Romanova, and G.P. Butenko was chosen to make the sample more homogeneous and exclude unhealthy models of child-parent relationships (for instance, pathological symbiosis, etc.).

2. The questionnaire "Analysis of family relationships" (ACB methodology) by E. G. Eidemiller and V. V. Yustitskis. Scales № 1-13 reveal the styles of upbringing as a system of influences. Scales №14-15 show the features of mutual influences in the family system.

\section{Results}

For the study, a group of women aged 27-35 years with one child aged 6-7 years was selected. Women are married and are satisfied with marriage. A group of women comprised 38 people, including (a) 15 women, gave birth naturally, (b) 12 - through a planned cesarean section, and 11 - as a result of an emergency cesarean section.

Based on the results of the questionnaire, statistically significant differences in the models of maternal behavior for six indicators were revealed (Table 1). For this, Fisher's Fcriteria was used at the significance level of $p=0.05$.

Table 1. Statistically significant differences in models of maternal behavior obtained with Fisher's F-test $(\mathrm{p}=0.05)$.

\begin{tabular}{|c|c|c|c|c|c|c|}
\hline \multirow{2}{*}{ Type } & \multicolumn{6}{|c|}{ ACB Scales (№) } \\
\cline { 2 - 7 } & $\begin{array}{c}\text { № 5 } \\
\text { requiressive } \\
\text { respon-ies (T+) }\end{array}$ & $\begin{array}{c}\text { № 6 } \\
\text { Insufficiency of } \\
\text { child's } \\
\text { requirements- } \\
\text { respon-ies (T-) }\end{array}$ & $\begin{array}{c}\text { Insufficiency of } \\
\text { requirements } \\
\text { and } \\
\text { prohibitions (3- } \\
\text { ) }\end{array}$ & $\begin{array}{c}\text { № 9 } \\
\text { Excessive } \\
\text { sanctions } \\
\text { (C+) }\end{array}$ & $\begin{array}{c}\text { № 10 } \\
\text { Minimal } \\
\text { sanctions } \\
\text { (C-) }\end{array}$ & $\begin{array}{c}\text { № 14 } \\
\text { Educational } \\
\text { insecurity of } \\
\text { the parent } \\
\text { (BH) }\end{array}$ \\
\hline $\begin{array}{c}\text { Natural } \\
\text { childbirth }\end{array}$ & 80,23 & 61,58 & 67,00 & 38,00 & 67,54 & 50,01 \\
\hline $\begin{array}{c}\text { Emergency } \\
\text { Cesarean }\end{array}$ & 67,35 & 61,11 & 73,60 & 61,67 & 63,16 & 59,09 \\
\hline $\begin{array}{c}\text { Planned / } \\
\text { Elective } \\
\text { Caesarian }\end{array}$ & $\mathbf{1 1 8 , 1 8}$ & $\mathbf{8 0 , 3 0}$ & $\mathbf{1 1 0 , 0 0}$ & $\mathbf{8 4 , 1 9}$ & $\mathbf{7 6 , 6 7}$ & $\mathbf{6 2 , 4 0}$ \\
\hline
\end{tabular}

By the degree of homogeneity of the six indicators, there are statistically significant differences between the three groups of women.

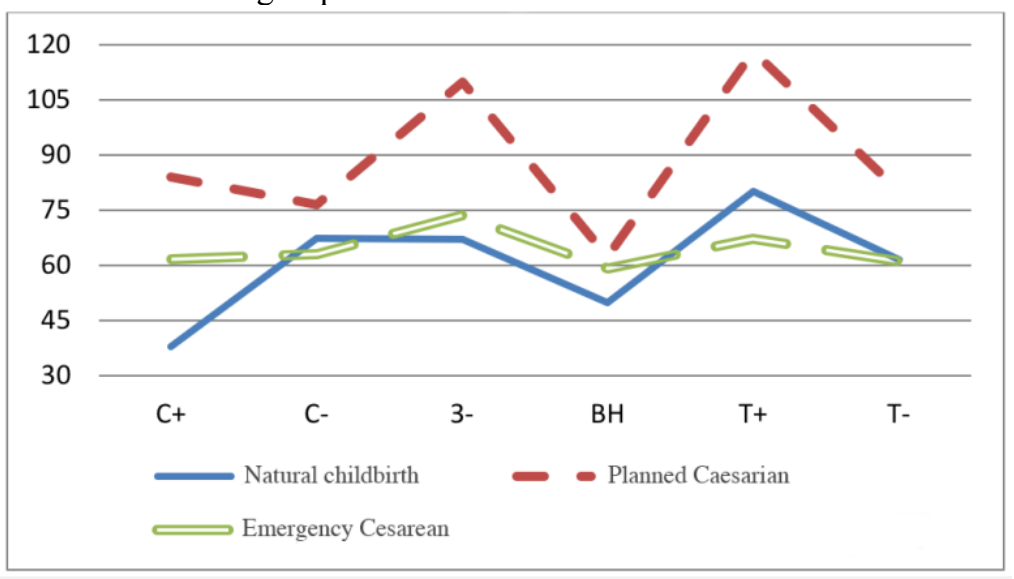


Fig. 1. Comparison of the models of maternal behavior

Table 2. Statistically significant intercorrelations of ABC method scales in subgroups that characterize models of maternal behaviour.

\begin{tabular}{|c|c|c|c|c|c|c|}
\hline $\begin{array}{l}1 \text { gr. } \\
\text { Natural childbirth }\end{array}$ & 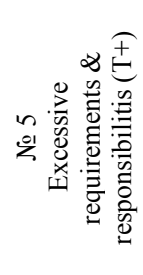 & 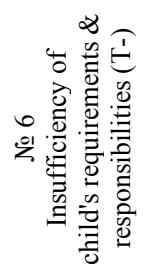 & 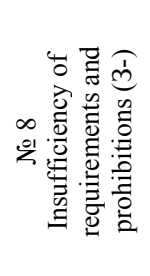 & 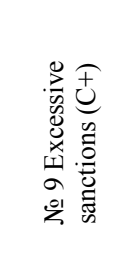 & 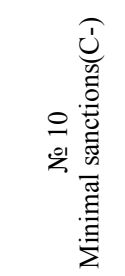 & 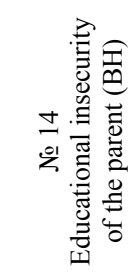 \\
\hline №5 $(\mathrm{T}+)$ & 1 & & & & & \\
\hline №6 (T-) & & 1 & & & & \\
\hline №8 (3-) & & 0,473028 & 1 & & & \\
\hline №9 $(\mathrm{C}+)$ & & & & 1 & & \\
\hline №10 (C-) & & & & & 1 & \\
\hline №14 (BH) & & & & & $-0,51089$ & 1 \\
\hline $\begin{array}{c}2 \mathrm{~g} . \\
\text { Planned Cesarean }\end{array}$ & №5 $(\mathrm{T}+)$ & №6 (T-) & №8 (3-) & №9 (C+) & №10 (C-) & №14 (BH) \\
\hline №5 $(\mathrm{T}+)$ & 1 & & & & & \\
\hline №6 (T-) & 0,716021 & 1 & & & & \\
\hline №8 (3-) & 0,636024 & 0,786205 & 1 & & & \\
\hline №9 $(\mathrm{C}+)$ & 0,827 & 0,661362 & 0,746748 & 1 & & \\
\hline №10 (C-) & 0,635344 & 0,631236 & 0,615558 & 0,575717 & 1 & \\
\hline №14 (BH) & & & & 0,306239 & & 1 \\
\hline $\begin{array}{c}3 \mathrm{gr} \\
\text { Emergency Cesarean }\end{array}$ & №5 $(\mathrm{T}+)$ & №6 (T-) & №8 (3-) & №9 (C+) & №10 (C-) & №14 (BH) \\
\hline № $5, \mathrm{~T}+$ & 1 & & & & & \\
\hline №5 $(\mathrm{T}+)$ & & 1 & & & & \\
\hline №6 (T-) & & & 1 & & & \\
\hline №8 (3-) & & & & 1 & & \\
\hline №9 $(\mathrm{C}+)$ & & & & & 1 & \\
\hline №10 (C-) & & 0,502489 & & & & 1 \\
\hline
\end{tabular}

\section{Discussion}

First, attention is drawn to the growth in the subgroups of indices of the educational insecurity of those mothers who underwent Caesarean section. As a rule, this scale is combined with a pronounced inadequacy in the consistency and uniqueness of the prohibition requirements of mothers being transmitted to a child.

For both the mother and the child, this pattern of behavior is unpredictable in terms of the inevitability of punishment for failing to fulfill duties or violating the prohibitions. This 
behavior frustrates the need for child safety and stimulates the formation of guilt in the mother, which in turn increases her educational insecurity. The study [9] showed that the burdensome relationship with the child with a sense of guilt in the mother stimulates alternately the manifestation in the behavior of authoritarian or hyper-behavioral patterns of behavior. In our study, in the Group of Emergency Cesarean, a significant positive correlation $(\mathrm{r}=0.50)$ was found between the scales of educational insecurity and the lack of requirements.

For the Group of Planned Cesarean, educational insecurity is moderately positively associated with excessive rigidity of sanctions $(r=0.30)$. We assume that the educational insecurity of the mother makes her afraid of stubbornness and the resistance of her children, engendering cruelty in punishment.

Impossibility of independent childbirth or heavy birth can become a traumatic emotional experience of women, forming their postnatal behavior. The response to a traumatic experience such as a Caesarean Section is manifested depending on the accessibility of this experience to the consciousness of the recipient. Among the external reactions of the mother, marking the psychological trauma of the mother in the situation of childbirth, there may be repressed aggression and, as a consequence, an emotional detachment from the child, manifested in inadequate reading of his/her emotional reactions.

If we follow the psychoanalytic methodology, we can assume that the mothers who survived the process of Cesarean Section have a high level of repressed aggression towards the child, because the pain and suffering that they experienced, were not compensated by the processes, biochemical changes that occur with the woman during natural childbirth (experiencing "anesthetic hormonal euphoria" after birth and establishing primary attachment between mother and child). We see (Fig. 1) that the severity of sanctions and punishments in the behavior of the mother becomes significantly more pronounced for the group of elective (planned) cesarean section.

A further interpretation of the correlations indicates that the educational rigidity of sanctions for the child turns out to be related either to overstated inadequate requirements or the absence of declared prohibitions. Verbally, the child is not told about the boundaries of rights and duties, which disorients him/her in relations with the mother and provokes a model of spontaneous punishment. In favor of the ambivalence of the maternal behavior style, there is also the presence of a reliable positive connection between the $\mathrm{C}+$ and $\mathrm{C}$ scales, and the fact that these scales are at different degrees of intensity but show a connection with the scales $\mathrm{T}+, \mathrm{T}-, \mathrm{Z}$.

For a subgroup of mothers who gave birth in a natural way, a completely different pattern of behavior is characteristic: with the growth of educational insecurity, the intensity of sanctions towards the child decreases, as well as the reduction of requirements is observed, the space of prohibitions narrows. Despite the pedagogical controversy of this model, in our opinion, it expresses the congruence of the state of the mother, who does not formulate the target points of education fully for herself and does not seek to win back her own anxiety through chaotic punishment of the child.

\section{Conclusion}

The data obtained in the pilot study allow us to formulate the following behavioral characteristics in relation to single children of 6-7 years in a subgroup of mothers who underwent a planned cesarean section. The increased density of intercorrelations shows that this group has an inconsistent model of behavior, the nuclear component of which is the educational insecurity of the mother, which generates rigidity of punishments. Probably, educational insecurity is formed due to an ambivalent attitude to the child and a high level of repressed aggression. 
We are aware of the many factors that need to be fully researches in order to get a more complete picture of the reality of the relationship between the mother and the child, unfolding in the long term after the mother's Cesarean Section. This encourages us to continue our research.

\section{Acknowledgments}

We are grateful to Julia V. Kungurtseva, a graduate of the Faculty of Psychology and Pedagogy of the Altai State University, who assisted in the collection of data, as well as Irina V. Molchanova, the main specialist, obstetrician-gynecologist of the Altai Krai Administration for Health and Pharmaceutical Activities for her interest in discussing the results of our study.

\section{References}

1. N. A. Zharkin, Medico-social and ethical problems of the cesarean section operation (Mother and Child, Moscow, 2004).

2. V. I. Kulakov, T. V. Chervakova, A. A. Tohiyyan. Bulletin of the Russian Association of Obstetricians-Gynecologists, 1 (1999)

3. D. G. German, V. M. Mikhlin, N. M. Korolkova, F. N. Korovkina, Journal of Neuropathology and Psychiatry Named After S. S. Korsakov, 9 (2008)

4. A. S. Sultanova, Consequences of the Caesarean section for the mental ontogeny of a child (Moscow, 2005)

5. Yu. V. Revyakina, I. V. Yaroslavtseva, Psychological Science and Education Psyedu.Ru, 7, 1 (2015)

6. G. G. Filippova, Journal of Practical Psychologist, 5 (2005)

7. V. I. Brutman, A. Ya. Varga, I. Yu. Khamitova, Psychological Journal, 21, 2 (2000)

8. I. V. Dobryakov, Perinatal psychology (Peter, St. Petersburg, 2010)

9. S. M. Pletneva, Family Psychology and Family Therapy, 2 (2007) 